\title{
Realization of Dry Cleaning Machine
}

\author{
Biqing $\mathrm{Li}^{1}$, Suping Jiang ${ }^{2,}$ a, ${ }^{,}$, Hongyan Zhang ${ }^{1}$ \\ ${ }^{1}$ School of Information and Communication Engineering, Hezhou University, Hezhou Guangxi \\ 542899, China; \\ ${ }^{2}$ Guangxi Talent International College, Qinzhou Guangxi 535000, China; \\ *, a229292710@qq.com
}

Keywords: GSM; STC89C52; DHT11; A clothes dryer.

\begin{abstract}
An alarm system automatic dryer control circuit SMS use STC89C52 microcontroller, DHT11 temperature sensor, display, relay, GSM technology components. GSM technology based on GSM module, send text messages to the relay, according to the SMS commands to control motor, when the clothes are temperature and humidity were collected by the detector and data processing through the transmission pin is transmitted to the single chip microcomputer.
\end{abstract}

\section{Introduction}

Nowadays, the average household dryer is common among families in many western countries. It is mainly used in combination with a washing machine, that is, clothes are dried by a dryer after washed by the washing machine, which can save time of use of clothing. However,it is not very popular in our country at present, it is only a small part of the family that can use the combination of a washing machine and a dryer, for which the main reason is that the price is expensive.

However, with the development of society and economy, the function of the dryer on the market in the future will be more comprehensive and the price will also be reduced. In this way, the dryer will reach tens of millions of families.

People tend to do other things after drying their clothes. This circumstance requires a clothes dryer that can automatically dry clothes. However, there are few dryers on the market can automatically dry clothes and promptly send text messages to remind users the progress of the clothes dry. This article describes the GSM-based dryer SMS alarm system.

\section{Design Scheme}

The design is mainly composed of STC89C52 microcontroller controller, DHT11 temperature and humidity sensor, GSM technology module and LCD1602 LCD module circuit. After the clothes' humidity and temperature real-time data is detected by DHT11 temperature and humidity sensor,it will be passed to the STC89C52 microcontroller, the relay controller will automatically request control the motor, and the temperature and humidity around clothes will be displayed on the LCD1602 LCD module when the motor starts working, then after the motor drying clothes and when the temperature and humidity meets the design requirements, the relay control dryer to automatically shut down, finally, GSM technology module will send SMS notification.

\subsection{Analysis of Power Part}

Since the operating voltage of the system components is $5 \mathrm{~V}$, and now most Android smart phones have a $5 \mathrm{~V}$ DC power supply USB interface as well as the computer USB output is $5 \mathrm{~V}$ voltage, so all modules of this system can be powered. Therefore, when designed power, the motor needs $22 \mathrm{~V}$, adopting directly plug in the general household power supply, in order to reduce costs and ease of use of other control circuit power, deciding to use a separate power supply and selecting the USB power supply. 


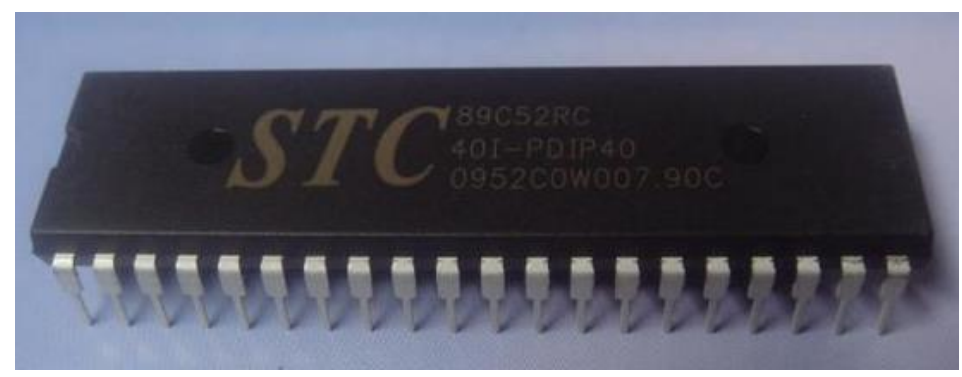

Figure 1. Physical Map of STC89C52

Port 0 (P0.0 P0.7): Port 0 is also used as the lower 8 bits for address and data multiplexing when accessing external programs and data memory. In this mode, $\mathrm{P} 0$ has an internal pull-up resistor. Port 0 is also used to receive the instruction byte while flash programming; the instruction byte [5] is output during program verification. It needs external pull-up resistor during program verification.

Port P2 (P2.0 P2.7): When accessing external program memory or reading external data memory with 16-bit address, $\mathrm{P} 2$ port sends out the upper eight bits address; in this case, $\mathrm{P} 2$ port uses strong internal pull-up to send "1" [3]; Port 2 outputs the contents of the P2 latch when accessing the external data memory using an 8-bit address; Port 2 also receives the upper 8-bit address byte and some control signals [5] while flashing programming and verifying.

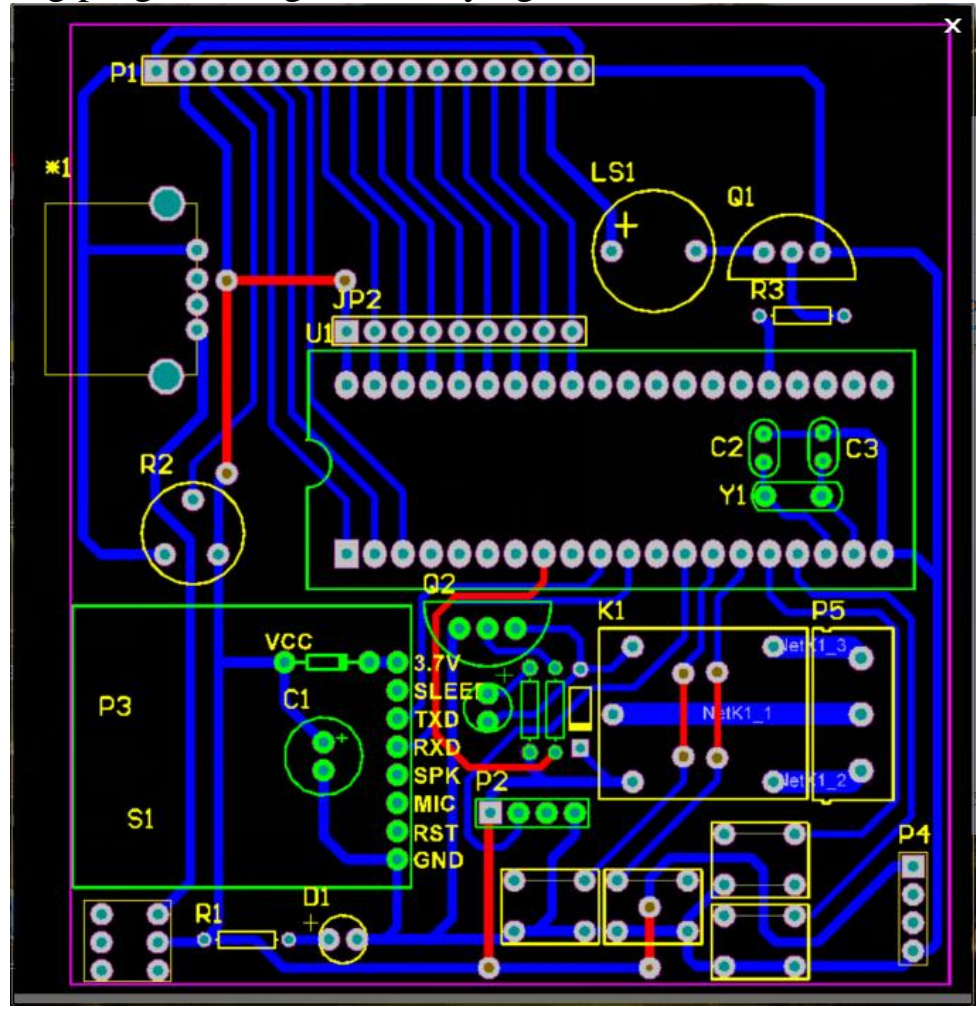

Figure 2. Port P2 (P2.0 P2.7):

\subsection{Crystal Oscillator Circuit}

The design of the crystal oscillator circuit is shown in Figure 4. There is an inverting amplifier used to form the internal oscillator in the STC89C52 microcontroller, XTAL1 and XTAL2 are the amplifier's input and output respectively, when externally connects ceramic oscillator, the capacitor $\mathrm{C} 2$ and $\mathrm{C} 3$ choose $40 \mathrm{pF} \pm 10 \mathrm{pF}$; the crystal oscillator frequency is generally chosen in the range of $1.2 \sim 12 \mathrm{MHz}$ in the STC89C52 system; external connected quartz crystal or ceramic oscillator and compensation capacitors $\mathrm{C} 2, \mathrm{C} 3$ form a parallel resonant circuit[9]; when connects quartz crystal externally, capacitor $\mathrm{C} 2, \mathrm{C} 3$ chooses $30 \mathrm{pF} \pm 10 \mathrm{pF}$; the size of external connected capacitors $\mathrm{C} 2, \mathrm{C} 3$ will affect the level of oscillator frequency, oscillation frequency stability, start-up time and temperature stability [9]; in the design of the circuit board, the crystal oscillator and capacitor should be close to the microcontroller in order to reduce parasitic capacitance to ensure stable and reliable oscillator work. 


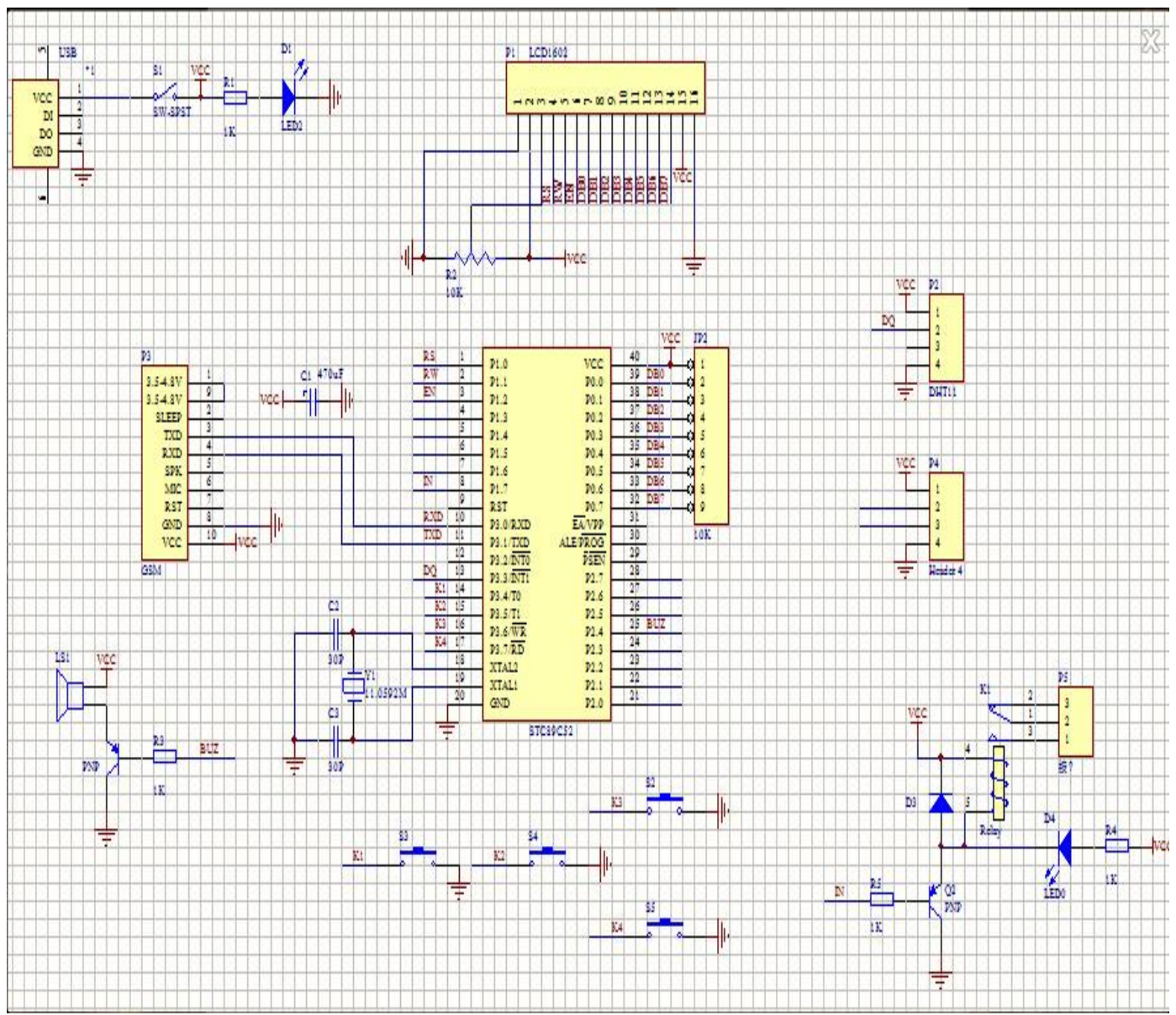

Figure 3. Crystal Oscillator Circuit

\subsection{Serial Communication Circuit}

Nowadays, the LCD screen can be seen everywhere. It has been widely used as the original display of electronic products, such as computers, multimeters and many household appliances, etc., which mainly for displaying numbers or images. There are many advantages in use of liquid crystal display in the microcontroller as the output of the original, such as relatively high quality of the display of output, small size, light weight, low power consumption and so on.

LCD1602 is a dot matrix LCD character LCD module specially designed for displaying letters, numbers, symbols, etc.. It is divided into two types, namely are with backlight and without backlight. The main technical parameters are display capacity: $16 \times 2$ characters, chip operating voltage: 4.5-5.5V, operating current: $2.0 \mathrm{~mA}(5.0 \mathrm{~V})$, the best working voltage of the module: $5.0 \mathrm{~V}$ the module, character size: $2.95 \times 4.35(\mathrm{~W} \times \mathrm{H}) \mathrm{mm}$.

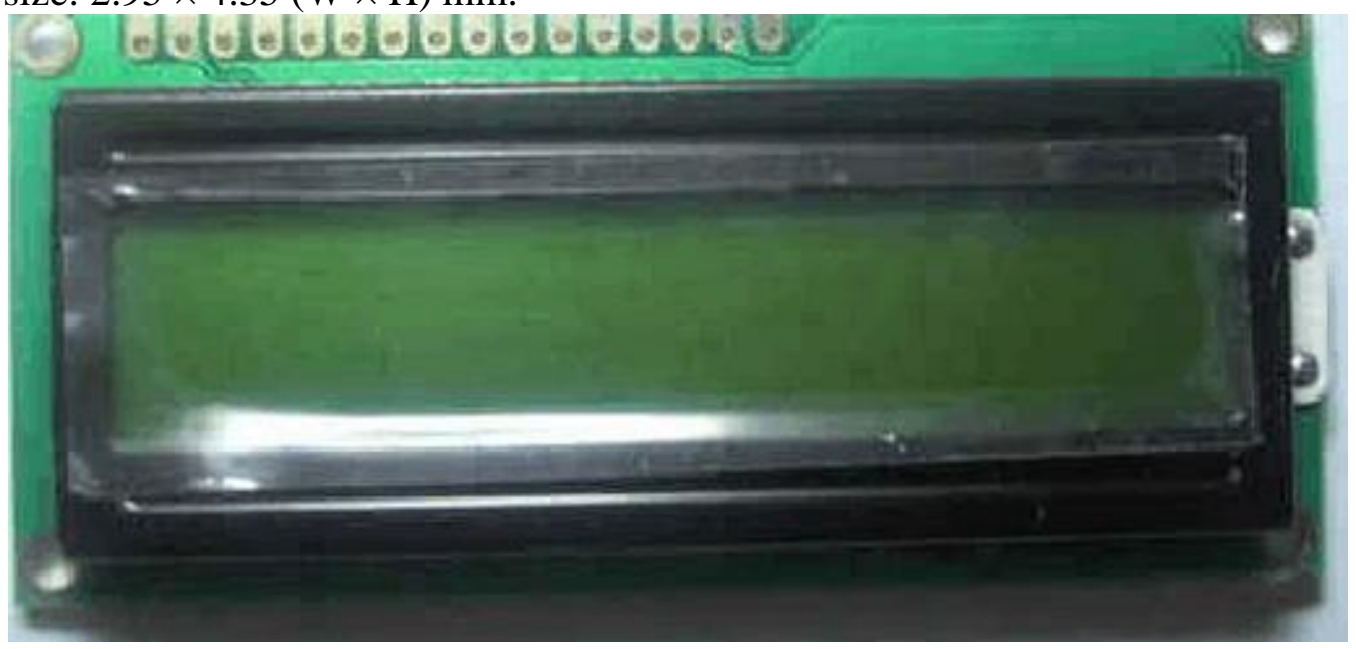

Figure 4. Physical Map of LCD1602 Viewing Screen 


\section{Software Design}

Only the reading is completed can the next judgment command be performed. If the read command is the same as the preset command, the corresponding code is executed. If not, the process returns to the previous step. In this way, the alarm SMS is set and user receives the number. After the number is set, the corresponding information will be fed back to the receiving side of the mobile phone according to the instruction and running status, and the receiver can send the message back according to their own intention after receiving the reminder, that is, sending ON to control the motor to open and sending OFF to turn off the motor.

A part of code as follow:

\#include<reg52.h>

\#include"lcd1602.h"

\#include"GSM.h"

\#include "key's"

\#include "dht11.h"

\#finder char

\#define char unsigned char

\#define unit unsigned into

\#endive

Sit JD=P1^7; /char data recive_buff[70];

Char Newel [12];

Char telnmb[12]="15857513121";

Bit flag=0;

Bit start flag $=0$;

Bit send flag=0;

Bit Flag;

Bit err $=0$;

Bit MsgFlag;

Sit beef $=\mathrm{P} 2 \wedge 4$;

Char tiao;

Char sec=0;

Unit Mind=3000;

Char Math=40;

Char Miner=30;

Char tinder;

Extern into wend, shade;

Void Ini_UART(void)

\{

SCON=0x50; //UART

$\mathrm{PCON}=0 \mathrm{x} 00 ; / / \mathrm{SMOD}$

TMOD $=0 \times 20 ; \quad / / T 1$

$\mathrm{TH} 1=0 \mathrm{xFD}$;

TL1=0xFD; //UART TR1=1;

$\mathrm{EA}=1$;

$\mathrm{ES}=1$;

\}

Void t0_init (void)

\{

TMOD $\mid=0 \times 01$;

$\mathrm{TH} 0=(65536-46080) / 256$;

$\mathrm{TL} 0=(65536-46080) \% 256$; 


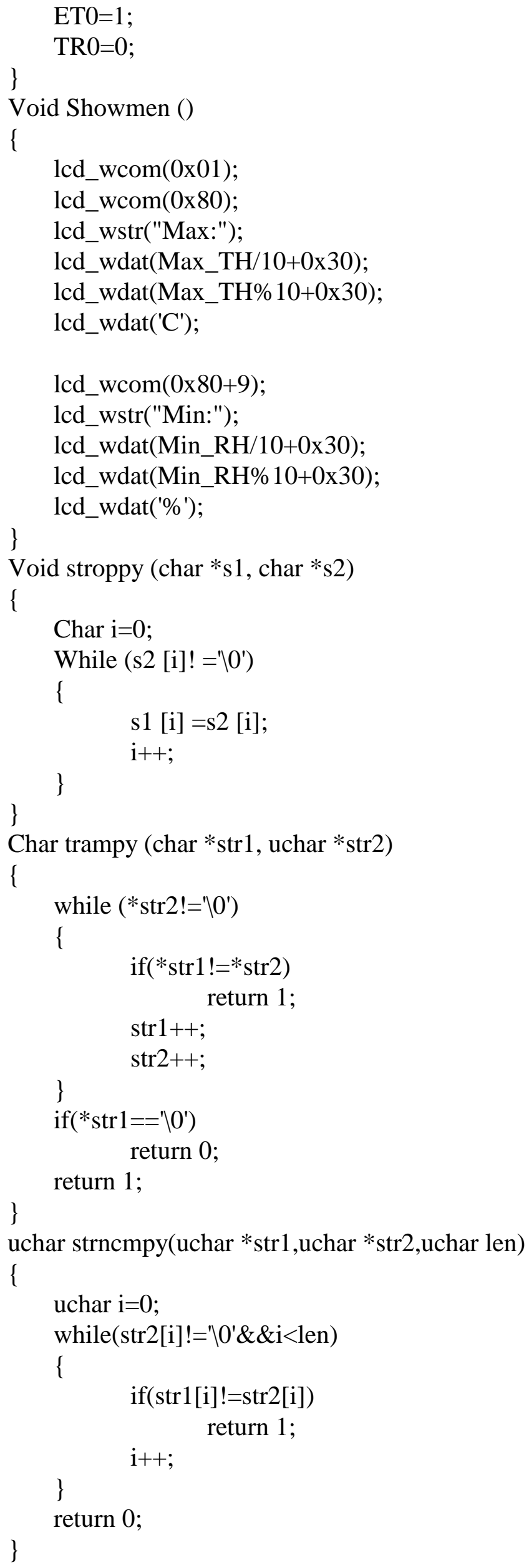




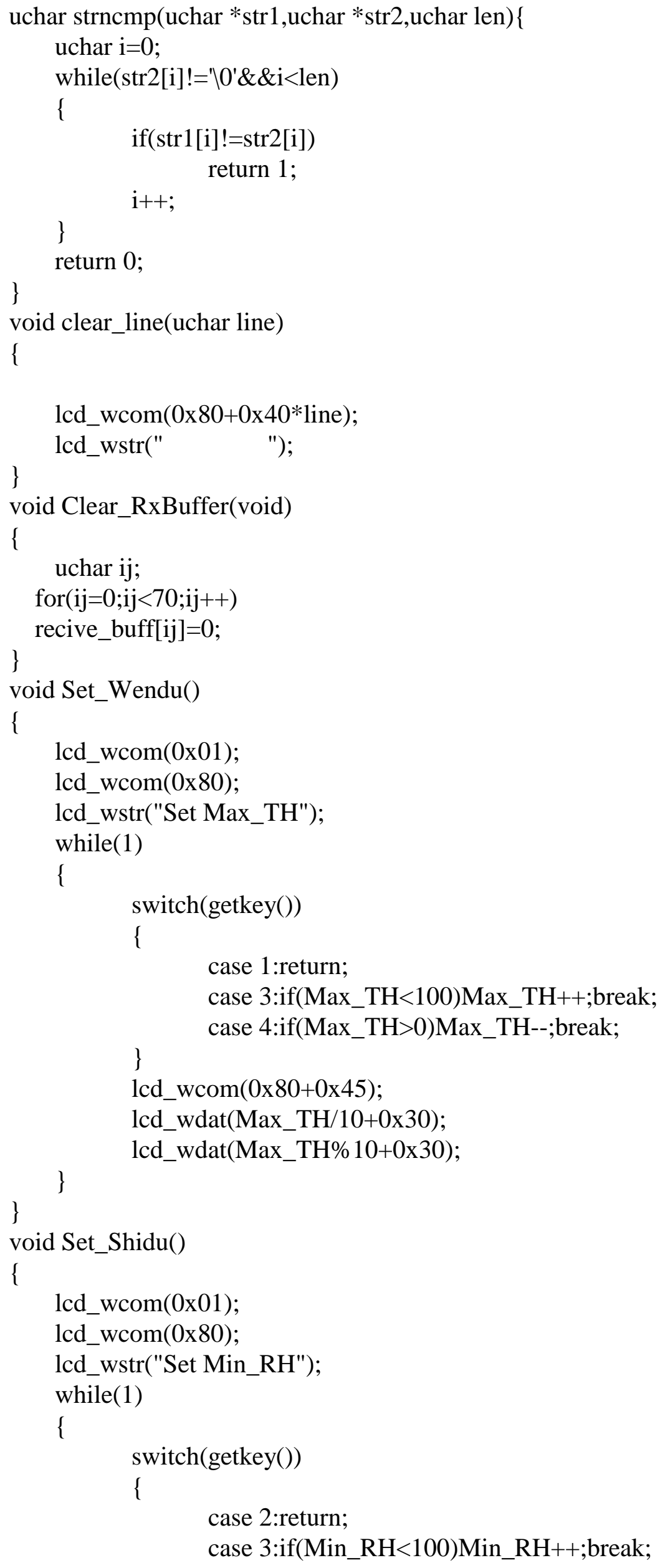




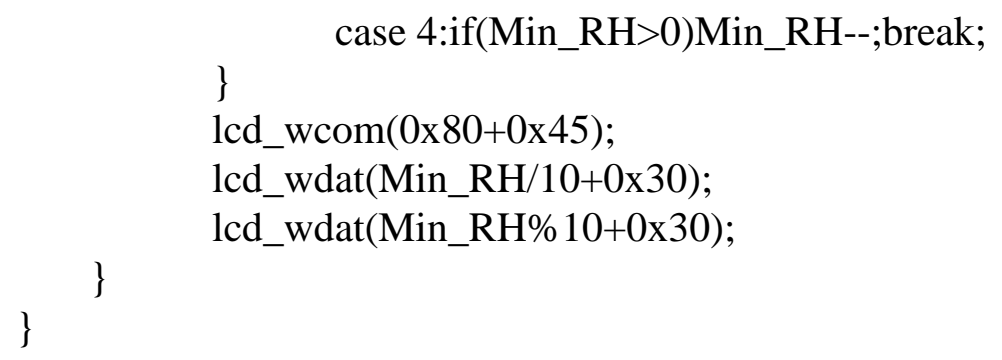

\section{Software Debugging}

It was relatively knotty when programming software programs in the very beginning,for did not know preset what command firstly, which needed to search information and ask teachers and classmates for just a little clue, and finally the program was programmed step by step. We used the C language, because it is not only more popular and easy to understand, but also very good to meet our system requirements. Programming used keil software in the software debugging, inputting software in the compiled program and compile to generate code, and then connect the circuit, downloading, reading and writing the program code into the STC89C52 microcontroller, and then debug module by module to see whether each module can achieve their own requirements of the function, if not, you need to check the program and the circuit diagram carefully, repeat in this way until each module can achieve its function. Then debug the entire program and have an overall test.

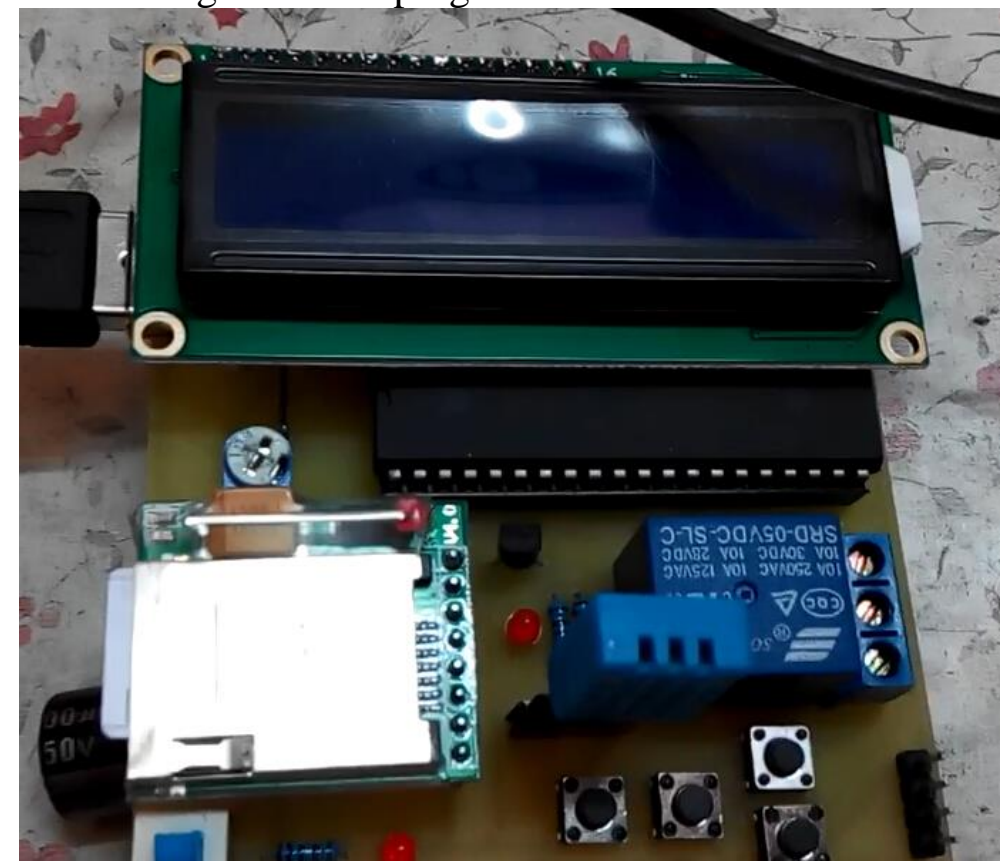

Figure 5. Hardware diagram

In the process of the completion of the debug, microcontroller would reset and reboot automatically sometimes, which may be caused by the instability of the software, also may be a welding problem, it would work again when it is reset.

\section{Summary}

Through months of continuous learning and practice, my design was finally completed. This work is supported the following fund:

2017 The student work subject program of Huizhou University: “college students' network addiction of the student work service research" (No, hzxysz201707).

2016 The higher education research subject project of Huizhou University: "between collaborative innovation researches of entrepreneurial talent cultivation system". 
2016 Guangxi university scientific research project:" Study on image processing based on digital compression sensing theory of intelligent robot" (No, KY2016YB454).

2017 college students' innovative entrepreneurial project: "The agricultural robot autonomous operations research based on machine vision"(No,201711838096) \&\&"Multi-functional autonomous agriculture robot development"(No,201711838121) \&\&"Research and development of navigation system for agricultural robot"(No,201711838008) \&\&"Research and development of data acquisition system and servo control system for mobile platform of agricultural robot" (No,201711838075) \&\&"Research and development of visual navigation system for agricultural robot test platform"(No,201711838076).

2017 Guangxi education science 'ten-three-five' planning project: "Based on set's ICT education platform of fusion, work-integrated learning education training mode research" (No, 2017B107).

\section{References}

[1] B.Q LI, Y.F LING, H.Y ZHANG, S.Y ZHENG: The Design and Realization of Cherry Tomato Harvesting Robot Based on IOT. International Journal of Online Engineering, 12(12), 23, (2016).

[2] B.Q LI, W.L GUAN, S.Y ZHENG, X.G Yue: Optimisation Design Of Corn Precision Seeder Based On Multi-Route And Multi-Channel Control. Journal Of The Balkan Tribological Association, 21(4a), 1215, (2015).

[3]B.Q LI, X.M YANG GUAN, S.Y ZHENG: Internet of Things-based Simulation Study on Lijiang River Water Environment Monitoring. Journal of Coastal Research,79, 1-5, (2017).

[4] B.Q Li, et al, Intelligent Control Management System and Its Application, in: Proceedings Of The 2016 International Conference On Economics And Management Innovations, Wuhan, China, 2016, Pp.68-71.

[5] B.Q Li, et al, Design and Implementation of Tanks War Game Based on the Android Platform, in: Proceedings Of The 2016 2nd Wrokshop On Advanced Research And Technology In Industry Applications, Dalian, China, 2016, PP.963-966.

[6] B.Q Li, et al, Design of a Tea Garden Antifreezing Control System, in: Proceedings of the 2016 6th International Conference On Machinery, Materials, Environment, Biotechnology And Computer(Mmebc), Tianjin, China, 2016, Pp.736-738.

[7] B.Q Li, et al, Design of Electronic Compass, in: PROCEEDINGS OF THE 2016 6TH INTERNATIONAL Conference On Machinery,Materials,Environment,Biotechnology And Computer(Mmebc), Tianjin, China, 2016, Pp.1240-1243.

[8] B.Q Li, et al, Research of Automatically Light-Adjusting Lamp, in: Proceedings Of The 2016 International Conference On Computer Engineering,Information Science \& Application Technology(Iccia 2016), Guilin, China, 2016, Pp.249-252.

[9] B.Q Li, et al, The Design and Realization of Fruit Harvesting Robot Based on IOT, in: Proceedings Of The 2016 International Conference On Computer Engineering,Information Science \& Application Technology (Iccia 2016), Guilin, China, 2016, Pp.261-264.

[10] B.Q Li, et al, A New Type of Automatic Opening and Closing Light-Operated Curtain, in: Proceedings Of The 2016 International Conference On Mechatronics Engineering And Information Technology(Icmeit), Xian, China, 2016, Pp.66-69.

[11] B.Q Li, et al, Design of the Intelligent Air Humidifier, in: Proceedings Of The 2016 International Conference On Mechatronics Engineering And Information Technology(Icmeit), Xian, China, 2016, PP.201-203. 
[12] B.Q Li, et al, The Design Implementation of the APP of Experiencing Guangxi Folk Custom, in: Proceedings Of The 2016 International Conference On Economics And Management Innovations, Wuhan, China, 2016, PP.47-50.

[13] S.Y Zheng, et al, Digital Display Design of Ethnic Clothing of Nanling, in: Proceedings Of The 4th International Conference On Mechatronics,Materials.Chemistry And Computer Engineering 2015(Icmmcce 2015), Xian, China, 2015, Pp.2805-2808.

[14] S.Y Zheng, et al, Design And Implementation Of Supermarket Personnel Management System Based On Java, In: Proceedings Of The 2015 International Conference On Ededucation,Management And Computing Technology(Icemct-16), Hangzhou, China, 2016, Pp.957-960.

[16] S.Y Zheng, et al, Brief analysis on“HeYuanTong”Campus Mobile Phone APP Design, in: Proceedings Of The 2015 5th International Conference On Computer Sciences And Automation Engineering, Sanya, China, 2015, PP.151-154.

[17]S.Y Zheng, et al, Social Work in Teen Addiction Correction Services Research Under the New Situation, in: Proceedings Of The 2015 4th National Conference On Electrical, Electronics And Computer Engineeering(Nceece 2015), Xian, China, 2015, Pp.252-255.

[18] B.Q Li, et al, The Design of Remote Temperature Monitoring System, in:International Conference on Green Energy and Sustainable Development, MAY 27-28, 2017, PP.20-22.

[19] B.Q Li, et al, Design of Portable Valuables Touch Alarm Circuit,in:International Conference on Advances in Materials, Machinery, Electronics ,2017, PP.27-32.

[20] B.Q Li, et al, Design and Implementation of a Simple Acousto Optic Dual Control Circuit, in:5th International Conference on Computer-Aided Design, Manufacturing, Modeling and Simulation,2017, PP.78-80.

[21] B.Q Li, et al, Design of electronic lock based on single-chip microcomputer, in:4th International Conference on Electrical and Electronics Engineering and Computer Science ,2017, PP.55-60.

[22] B.Q Li, et al, The Design of Chicken House Electronic Intelligent Lighting Apparatus,in:International Conference on Mechanical, Electronic, Control and Automation Engineering,2017, PP.15-20.

[23] B.Q Li, et al, Office Automation Sub-Summary of the Work and the Project Management System,in:International Conference on Mechanical, Electronic, Control and Automation Engineering,2017, PP.46-48.

[24] B.Q Li, et al, The Design of Intelligent Heat Dissipator Control Circuit,in:Proceedings Of The 2017 2nd International Conference On Materials Science, Machinery And Energy Engineering,2017, Pp.22-25.

[25] B.Q Li, et al, The Design of IPv6's Transitional Scheme in University,in:International Conference on Materials Science, Energy Technology, Power Engineering (MEP), 2017, PP.91-93.

[26] B.Q Li, et al, The Personal Receiving Document Management and the Realization of Email Function in OAS,in:International Conference on Materials Science, Energy Technology, Power Engineering (MEP) ,2017, PP.121-123.

[27] S.Y Zheng, et al, Design and Implementation of an Audio Indicator,in: 5th International Conference on Computer-Aided Design, Manufacturing, Modeling and Simulation,2017, PP.21-23.

[28] S.Y Zheng, et al, Implementation and Application of ACL in Campus Network, in: International Conference on Advances in Materials, Machinery, Electronics ,2017, PP.151-153. 
[29] S.Y Zheng, et al, The Design of Liquid Drip Speed Monitoring Device System Based on MCU,in:International Conference on Green Energy and Sustainable Development, MAY 27-28, 2017, PP.51-53.

[30] S.Y Zheng, et al, The Design of Hearing and hypnosis all-in-one Machine, in:International Conference on Mechanical, Electronic, Control and Automation Engineering,2017, PP.66-68.

[31] S.Y Zheng, et al, Campus Network Security Defense Strategy,in:International Conference on Mechanical, Electronic, Control and Automation Engineering,2017, PP.30-33.

[32] S.Y Zheng, et al, Design and implementation of multifunctional charger,in:International Conference on Materials Science, Energy Technology, Power Engineering (MEP) ,2017, PP.71-73. 